\title{
Representação, crise \\ e mal-estar institucional
}

Marco Aurélio Nogueira*

Resumo: Tomando como ponto de partida a constatação de que as democracias contemporâneas não podem funcionar sem parlamentos ativos, o artigo procura dialogar com a recorrente imagem de uma "crise de representação" no Estado contemporâneo, ou seja, com as dificuldades que esse instituto tem manifestado para se atualizar e permanecer cumprindo funções estratégicas nas complexas sociedades dos dias correntes. Para tanto, considera que os problemas da legitimidade nos sistemas políticos atuais estão relacionados com a questão da crise do Estado e da política impulsionada pelas novas formas adquiridas pela estrutura econômica e pela sociabilidade do capitalismo contemporâneo. Sua hipótese de fundo sugere que as transformações da sociedade capitalista - a hipermodernidade - puseram em xeque e ultrapassaram a representação, deixando-a defasada e com sérias dificuldades operacionais.

Palavras-chave: representação, democracia, Estado, política, parlamento.

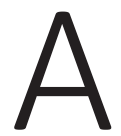

s democracias contemporâneas não podem funcionar sem um Poder Legislativo forte e atuante, mas os parlamentos, hoje em dia, estão tão perturbados pelas circunstâncias gerais da vida e por suas repercussões que passam a ter cada vez mais dificuldades operacionais, políticas e institucionais para cumprir suas funções. Tal paradoxo não respeita fronteiras, regimes político-administrativos ou jurisdições: é um fato universal, presente em diferentes sociedades, marca adquirida pelo Estado representativo no correr do tempo da modernidade. Ao mesmo tempo em que são uma condição básica para o bom funcionamento dos regimes democráticos e, portanto, para o bom governo das sociedades, os parlamentos projetam-se no cenário como instituições relativamente engessadas, com poucas folgas para deliberar livre e produtivamente, para estabilizar de modo eficiente seu curso e para ajudar a compor o consentimento político e a legitimidade. Estão hoje, em boa medida, comprimidos entre o decisionismo governamental e as exigências incansáveis do mercado, de um lado, e as pressões, a fragmentação e o espontaneísmo social, de outro. Sem os parlamentos, as democracias não funcionam, mas os parlamentos não estão conseguindo operar à altura das necessidades da democracia.

A situação remete à discussão recorrente sobre a emergência de uma "crise de representação" no Estado contemporâneo, ou seja, sobre as dificuldades que esse instituto tem manifestado para se atualizar e permanecer cumprindo funções estratégicas nas complexas sociedades dos dias correntes. Tem a ver, portanto, com o problema da legitimidade nos sistemas políticos atuais e, desse modo, com a questão da crise do

\author{
* Professor titular \\ de teoria política \\ e diretor do \\ Instituto de Políticas \\ Públicas e Relações \\ Internacionais \\ (IPPRI), da \\ Universidade \\ Estadual Paulista \\ (Unesp). Autor, \\ entre outros, \\ de As ruas e a \\ democracia. Ensaios \\ sobre o Brasil \\ contemporâneo \\ (Brasília; Rio de \\ Janeiro: FAP. \\ Contraponto, 2013). \\ <nogueiramarcoa@ \\ gmail.com>.
}


Estado e da crise da política impulsionadas pelas novas formas adquiridas pela estrutura econômica e pela sociabilidade do capitalismo contemporâneo - aquilo que se costuma associar aos fenômenos da globalização e da radicalização da modernidade.

Embora seja expressão consagrada e largamente empregada sempre que a situação política de países democráticos falha ou deixa de responder adequadamente, "crise de representação" não se traduz de modo uníssono. Há muita divergência quanto a seu estatuto e especialmente quanto a sua potência explicativa. Se os sistemas democráticos e a política moderna têm estruturas dinâmicas e humores variados, faria sentido falar em "crise de representação" para qualificar um ou outro de seus espasmos disfuncionais? A hipótese subjacente à ideia de que a representação está em crise afirma que ingressamos em uma fase de profunda transformação sistêmica na qual a representação democrática conhece um desgaste particular e profundo, a ponto de não ser mais capaz de responder às expectativas com que foi criada. Mas isso significaria necessariamente que a representação perdeu sentido e corre risco de vida? Não poderia ser também um indício de que ela está a se reconfigurar?

Não é necessário detectar a presença de uma "crise" para se constatar que a representação conhece dias turbulentos. É bastante razoável a conhecida hipótese de que estamos a assistir não tanto a uma crise, mas a uma "metamorfose da representação" (Manin, 1996). A constatação de que a representação não está à beira da morte serve para que se desarmem os diagnósticos apocalípticos, mas não diminui os prejuízos que decorrem do mau funcionamento dos sistemas representativos. Uma metamorfose, afinal, implica um desarranjo na estrutura de um dado corpo: o vetor da transformação desorganiza o que estava organizado e funcionava dentro de certo padrão. Nessa perspectiva, estaríamos a presenciar uma situação de reorganização dos sistemas representativos a partir de uma "crise" que se instalou em seus fundamentos, ou ao menos em alguns deles, considerados como essenciais. A crise, portanto, é na e não da representação.

Parte da dificuldade para que se resolva de forma cabal a questão tem a ver com a ideia mesma de representação, invariavelmente marcada por discrepâncias de entendimento, ora confundida com democracia, ora vista como princípio oposto à participação e à democracia direta, como forma de governo indireto e elitista na qual o povo não seria bem-vindo ou teria pouco protagonismo. Em muitas dessas operações perde-se o caráter complexo da representação (um sistema de governo composto por múltiplas instituições) e abandonam-se suas relações com a sociedade e a história, ou seja, a modelagem que a experiência social concreta faz do sistema.

O próprio verbo representar não é de imediata tradução e compreensão. Associa-se à ação de pessoas que representam pessoas, das quais recebem um mandato ou uma delegação, como no caso específico da representação política de que queremos nos 
ocupar aqui. Mas tem a ver, também, com a ação de "retratar" ou "figurar" artisticamente alguma situação, assim como com o ato de "interpretar" um papel, como no caso do cinema e do teatro ou mesmo da vida cotidiana. Ainda que essas sutis gradações de significado convirjam para a ideia de algo ou de alguém que se apresenta ou se reapresenta em um dado ambiente, é evidente que elas ocultam processos e conteúdos distintos, invariavelmente associados a pessoas, espaços, procedimentos, instituições e símbolos distintos (Pitkin, 2006).

Além disso, o fato de, em política, a ação de representar adquirir materialidade sistêmica - isto é, somente funcionar mediante um conjunto de regras e instituições -, fez com que a representação acompanhasse as transformações das sociedades e fosse, assim, ficando sempre mais complexa, carregada de atores e espaços difíceis de serem mapeados de forma simples: governantes, governados, gestores, técnicos, cidadãos, eleitores, parlamentares, partidos políticos, sistemas eleitorais, instituições do Executivo, do Legislativo e do Judiciário, organismos do mercado, do mundo do trabalho e da sociedade civil (a representação dos interesses). As tradicionais contraposições entre democracia eleitoral e democracia substantiva, entre democracia representativa e democracia direta, entre "representar a" e "participar de", são tentativas não propriamente bem sucedidas de ordenar esse universo.

Por fim, a representação mantém relações de grande proximidade com a democracia, a ponto de boa parte da literatura que se dedica ao tema tratá-lo quase sempre como expressão da representação democrática, ainda que se preocupando em distinguir representação e democracia. Pode-se ver isso, por exemplo, no meticuloso trabalho de Bernard Manin. Ele circunscreve a representação a um regime de governo, que pode assumir formas mais ou menos democráticas, mais ou menos participativas. Mas o governo representativo, em sua conceituação, tem princípios claros e específicos, que o aproximam fortemente do governo democrático: 1. designação dos governantes mediante eleições em intervalos regulares; 2 . independência relativa dos governantes vis-à-vis a vontade dos eleitores; 3 . possibilidade de que os governados exprimam suas opiniões e suas vontades políticas sem que elas tenham de ser submetidas ao controle dos governantes; 4. submissão das decisões públicas à prova do debate público. (Manin, 1996: 17-18). Nesse elenco, encontramos quase integralmente a famosa "definição mínima de democracia" de Norberto Bobbio, na qual estão presentes algumas regras procedimentais básicas: sufrágio universal, pluralismo, princípio de maioria e respeito às minorias (Bobbio, 2000).

Ambas são concepções que se fixam no plano conceitual e normativo, mas que se mostram abertas à dinâmica histórico-social e buscam verificar em que medida regras e princípios assumem características particulares e entram em maior ou menor sintonia com as circunstâncias sociais, em suma, reagem a elas. 
Bobbio, nesse particular, insistiu sempre que os princípios doutrinários da democracia liberal, ao dialogarem com a realidade das sociedades capitalistas avançadas, mostraram-se quase sempre como "promessas não cumpridas" e que não tinham como ser cumpridas, dado o tamanho dos obstáculos que a elas se antepuseram. Ao predomínio do indivíduo soberano opôs-se a poliarquia das sociedades sempre mais plurais; ao mandato independente, não vinculado, opuseram-se os interesses particulares, regra geral organizados de modo corporativo; à expansão da democracia opôs-se a persistência de espaços fechados à decisão democrática, do mesmo modo que o "Estado invisível" dificultou o controle público do poder e a transparência política (Bobbio, 2000).

Por uma via ou por outra, portanto, esses autores caminham na direção da representação democrática, no sentido específico atribuído a esse conceito por Nadia Urbinati: "um modo de participação política que pode ativar uma variedade de formas de controle e supervisão dos cidadãos". Trata-se, nessa formulação, de uma forma de governo - a democracia representativa - que não é idêntica nem à "democracia eleitoral", nem à "democracia direta", até por se mostrar mais eficiente e mais democrática do que elas. A representação política democrática, assim, organiza-se como "um processo circular (suscetível ao atrito) entre as instituições estatais e as práticas sociais", afirmando-se como "um modo de a democracia recriar constantemente a si mesma e se aprimorar" (Urbinati, 2006: 191-192).

Tais explorações dos problemas de realização da representação democrática em sociedades complexas não sugerem a imagem de uma progressiva e irrefreável demolição do parlamento, mas sim a presença de uma situação de impasse e paralisia, em si mesma solicitante de um processo de revisão do funcionamento do Poder Legislativo e de suas relações com o Estado e a sociedade.

A abordagem crítica do paradoxo mencionado no início do presente texto - qual seja: o de que as democracias contemporâneas não podem funcionar sem parlamentos atuantes mas os parlamentos, hoje em dia, enfrentam graves dificuldades operacionais - pode seguir dois caminhos não excludentes. O primeiro deles valoriza a dimensão legal, ou seja, focaliza o arcabouço constitucional do Estado, desdobrando-se em uma visão concentrada na dimensão sistêmica específica dos parlamentos, explorando tanto os regimentos internos e as modalidades de funcionamento e de organização administrativa das casas legislativas quanto seus "recursos humanos" (classe política, assessores técnicos e servidores administrativos). Alojam-se aqui as análises que se dedicam à avaliação do formato e ao funcionamento do sistema eleitoral e do sistema partidário. O paradoxo seria explicado, assim, como derivando essencialmente de um problema de déficit interno. Quer dizer, os parlamentos estariam pecando ou por terem regimentos ruins, ou por terem quadros técnicos e políticos de baixa qualidade, ou não tão qualificados quanto seria necessário pelo tamanho dos desafios. 
É um caminho que faz sentido e revela pontos potenciais de estrangulamento. Se em uma dada sociedade existem problemas de adequação das leis eleitorais e partidárias, por exemplo, é evidente que haverá uma repercussão negativa disso na composição e na atuação dos parlamentos. Do mesmo modo, se os processos seletivos que são seguidos para recrutar os quadros técnicos, políticos e administrativos dos parlamentos não forem bem organizados e bem conduzidos, a instituição tenderá a responder com deficiência àquilo que o Estado e a sociedade esperam dela.

Um segundo caminho é mais abrangente. Seu foco dirige-se essencialmente para as condições gerais em que se vive hoje no mundo contemporâneo e de modo particular nas diferentes sociedades nacionais. O pressuposto, aqui, é que a vida moderna se radicalizou e está assumindo formas que são em si mesmo desafiadoras para toda e qualquer ação organizada, para toda e qualquer instituição. Nas atuais condições da vida moderna, não seriam portanto apenas os parlamentos que sofreriam para operar e funcionar bem. Todas as organizações apresentariam déficits semelhantes e estariam imersas em uma idêntica dinâmica de "sofrimento" (Nogueira, 2011). O problema dos parlamentos não está determinado exclusivamente, nem principalmente, por falhas de legislação ou de recursos humanos. Seria, ao contrário, uma derivação das dificuldades de sintonia entre as circunstâncias da vida, as expectativas sociais e as orientações organizacionais.

Esse segundo caminho sugere, assim, que as transformações da sociedade capitalista - a hipermodernidade - puseram em xeque a representação e a ultrapassaram, deixando-a defasada e com graves dificuldades operacionais.

\section{Radicalização do moderno}

Estamos imersos em um conjunto de circunstâncias que está a formar um modo de vida de características globais, que tende hoje a plasmar o planeta e a afetar simultaneamente suas diferentes regiões, ainda que fazendo isso de modo radicalmente assimétrico e contraditório. Afirma-se globalmente um processo objetivo de reorganização da economia, das relações sociais, das instituições políticas e das formas de pensamento, convulsionando a condição humana no seu todo. Com esse processo objetivo interagem diferentes projetos políticos, que buscam direcionar aquela reorganização e dos quais o neoliberalismo tem-se mantido na dianteira, ainda que não necessariamente em linha ascendente.

A novidade do mundo atual não deriva do fato de ser global. A rigor, o mundo sempre foi global e os homens sempre tiveram a pretensão de abarcar o universo. Essa foi uma imaginação recorrente, em sintonia com a realidade histórica e especialmente com os processos reais da modernização capitalista. O capitalismo jamais se conteve 
em si: afirmou-se sempre mediante ciclos expansionistas, de conquista de novos mercados, de novas oportunidades, de novos "fiéis". A novidade é que hoje a globalização se radicalizou. Ela conseguiu, digamos assim, ir a seu próprio limite, incluindo todas as partes, todos os povos e grupos sociais. Hoje, não há ninguém que possa se apresentar como se estivesse imune aos efeitos da globalização. Não se trata de escolha, consciência ou opção. Muitos dos mais globalizados são também os que estão mais excluídos. São os miseráveis da Terra, os desempregados, aqueles que têm menos oportunidades para viver com dignidade no mundo e que sentem na carne os efeitos perversos da globalização.

Isso significa que a globalização capitalista passou a integrar de modo desigual as diversas partes da Terra. Incorporou os territórios, reconfigurando-os como parte de uma única e mesma operação econômica, de um único e mesmo mercado mundial, teatro ativado por amplos sistemas de informação e comunicação e monitorado pelo grande capital industrial e financeiro transnacional. Ao conectar as diversas regiões e os diferentes povos graças a gigantescas redes de comunicação, informação e entretenimento, o processo foi facilitando o descolamento das comunidades de seus territórios básicos de assentamento. Foi, por assim dizer, "dessencializando" os territórios físicos, fazendo com que eles passassem a perder relevância e a escapar do controle dos poderes instituídos pelos Estados nacionais.

A desterritorialização já é, por si só, um relevante fator de mudança e reorganização, na medida mesma em que, ao se operar em condições de império do mercado e do grande capital, subtrai bases físicas e condições de estabilidade dos poderes instituídos. Pode ser tomada como símbolo de uma era mais móvel, mais dinâmica e menos estruturada, e na qual um dos pilares constitutivos da modernidade - o Estado nacional - passa a ser fortemente questionado.

O Estado moderno nasceu territorializado: como poder, monopolizou a "coerção física legítima em um dado território" (Max Weber). Fechou-se, portanto, em fronteiras controladas e vigiadas, dentro das quais se organizou e a partir das quais se proclamou soberano. O povo, em seu interior, tornou-se igualmente territorializado, assentado, protegido por direitos e prerrogativas específicas, mas também controlado e "administrado". O poder político, desse modo, nacionalizou-se e se concentrou.

Tal padrão de sociabilidade foi progressivamente se reciclando e se aprofundando em termos capitalistas. Conheceu a expansão urbano-industrial, os efeitos de inúmeras revoluções tecnológicas, o impacto da afirmação das massas e da socialização política, passou por ajustes no modo de produção, de acumulação e de regulação, conviveu com a constituição do moderno Estado constitucional representativo, com o Estado liberal e com o Estado de bem-estar social keynesiano. Evoluiu como sistema com- 
plexo sem perder as raízes territoriais, ou seja, repondo-se sistematicamente como experiência nacional.

Nas últimas décadas do século XX, esse padrão de sociabilidade atingiu um ponto de esgotamento e de superação. Um forte processo de radicalização fez com que a modernidade (ocidental) se consolidasse em escala global e explicitasse seus componentes típicos (a individualização, o progresso técnico, a produtividade, os direitos humanos, a democratização), ganhando extraordinária complexidade, maior dinamismo e grande fluidez. O mundo capitalista tornou-se transnacional, hipermercantilizado e superconectado, configurando-se como sistema que ultrapassa os Estados nacionais e que se combina com a emergência de sociedades mais dinâmicas, fragmentadas e diferenciadas, relativamente "soltas" no espaço, assentadas em territórios que perdem relevância.

"Perder relevância" não quer dizer, evidentemente, ficar sem significado ou importância, mas sim ter menos peso na definição de certas questões e na resolução de certos problemas. Para falar de modo simples, os territórios nacionais deixaram de ser a base a partir da qual os governos definem suas políticas econômicas, que passam sempre mais a seguir orientações do mercado mundial e da dinâmica transnacional. Do mesmo modo, as populações tendem a reduzir a lealdade a seus Estados e a seus governantes, na medida em que eles se mostram menos capacitados para responder a suas demandas e expectativas:

\begin{abstract}
A tentativa de o Estado reafirmar seu poder na arena global pelo desenvolvimento de instituições supranacionais acaba comprometendo ainda mais sua soberania. E os esforços do Estado para restaurar sua legitimidade por meio da descentralização do poder administrativo, delegando-o às esferas regionais e locais, estimulam as tendências centrífugas ao trazer os cidadãos para a órbita do governo, aumentando, porém, a indiferença destes em relação ao Estado-nação (Castells, 1999: 287).
\end{abstract}

Ou seja, tanto pelas respostas que dá à pressão transnacional, quanto pelas que dá às pressões de seus cidadãos, os governos nacionais se enfraquecem. Ao serem condicionados por essas respostas, os Estados-nação perdem em termos de regulamentação, implementação de políticas, coordenação e soberania. Seu aparato e seu pessoal administrativo ficam com menos condições de interferir no jogo global e de interagir com as comunidades a que estão vinculados.

Os Estados nacionais se ressentem da fuga dos territórios. Persistem como figuras-chave do mundo e da vida, pois tudo ainda é feito em termos nacionais - a economia, a política, a cultura e as paixões são nacionais. Por sobre esse movimento de reitera- 
ção, porém, há uma espécie de diluição daquilo que está nacionalmente estabelecido. A conectividade geral liga grupos e pessoas em redes que flutuam sobre os territórios e sobre aquilo que está instituído. Os poderes não conseguem mais submeter a controle a dimensão territorial nacional. A diluição retira das organizações a possibilidade de protagonizarem a organização da vida.

Ao adquirir formas e dinâmicas "líquidas" (Bauman), a modernidade levou ao limite sua característica de fazer com que tudo o que é sólido se volatilize e tudo o que é sagrado seja profanado (Marx, Engels). Não se comprime mais em espaços predefinidos: está livre, impossibilitada de ser contida, como a água, como um tsunami. Tensões, contradições, crises e acidentes localizados tendem a ingressar em um circuito de amplificação que leva as coisas para rumos que não prevíamos e que não conseguimos controlar.

\begin{abstract}
O derretimento dos sólidos [traço permanente da modernidade] adquiriu portanto um novo sentido, e, mais que tudo, foi redirecionado a um novo alvo, e um dos principais efeitos desse redirecionamento foi a dissolução das forças que poderiam ter mantido a questão da ordem e do sistema na agenda política. Os sólidos que estão para ser lançados no cadinho e os que estão derretendo neste momento, o momento da modernidade fluída, são os elos que entrelaçam as escolhas individuais em projetos e ações coletivas - os padrões de comunicação e coordenação entre as políticas de vida conduzidas individualmente, de um lado, e as ações políticas de coletividades humanas, de outro (Bauman, 2001: 12).
\end{abstract}

Um reflexo imediato disso é que os centros perdem capacidade operacional. Os órgãos se tornam menos funcionais. Passam a apresentar problemas de funcionamento mais frequentes e mais difíceis de serem resolvidos. Ocorre um enfraquecimento múltiplo que deixa as organizações quase que em funcionamento inercial. Os núcleos de direção existem, estão formalmente estabelecidos, funcionam, as pessoas sabem que estão ali, reportam-se a eles e os obedecem, ao menos parcialmente. Mas os núcleos, para fazer com que suas decisões, seus comandos e suas ordens sejam aceitos, precisam despender grande energia, tanto em termos financeiros quanto em termos operacionais e existenciais.

A crise do Estado nacional imposta pela globalização e pela modernidade líquida produz abalos na institucionalidade política contemporânea, ao mesmo tempo em que pressiona no sentido da invenção constante de novas instituições, dentro e fora das nações. Nada indica que os Estados nacionais deixarão de existir, mas está certamente em aberto a questão de saber como se reorganizarão para assumir um novo papel no cenário do século XXI. Dá-se, no fundo, um deslocamento: a política deixa de se identificar com o Estado-instituição e é obrigada a se abrir para uma sociabilidade 
explosiva e multifacetada, sendo convidada a rever seu sentido, seus sujeitos e seus marcos institucionais.

Um dos efeitos dessa situação é que as casas legislativas ficam saturadas de demandas e expectativas, ao mesmo tempo em que passam a dispor de espaços de atuação mais comprimidos. Funcionam com maior dificuldade e são obrigadas a despender maior esforço para cumprir suas funções, desgastando-se com isso. Mergulham em constantes ciclos de deterioração e têm seus ritos e procedimentos questionados, tanto pelos cidadãos como pelos demais poderes instituídos. A imagem negativa que acabam por exibir é apenas um subproduto dessa situação.

O parlamento é uma instituição essencialmente política. Sofre, antes de tudo, o impacto do avanço do processo de racionalização crescente típico das sociedades ocidentais modernas, que trouxe consigo uma cultura que impõe sacrifícios enormes à política, na medida mesma em que submete todos os atos, todas as decisões e todos os focos de vida associativa ao ritmo da racionalidade instrumental, do cálculo, da burocratização.

São tantos e tão complexos os problemas com que se defrontam as comunidades que o recurso aos peritos tornou-se inevitável. O arsenal com que se opera no círculo das decisões intimida as pessoas. Em decorrência, o cidadão perde terreno para o especialista, que se converte no personagem central da vida política (Bobbio, 2000) e passa a imprimir seus valores e seus procedimentos ao conjunto do Estado, modificando, por exemplo, os termos e a estrutura mesma do discurso político. Com isso, o debate público é tecnicizado, tornando-se cifrado, tedioso, incompreensível para a maioria das pessoas. Decodifica-se apenas o discurso grosseiro e apelativo. Quando o debate se explicita, despoja-se de magia e afasta os interlocutores.

Os defeitos do sistema político ficam assim amplificados; impedem que se tomem medidas para sanear a política, limpá-la da sujeira que se vai acumulando, devolver-Ihe coerência, clareza e simplicidade; não ajudam a injetar-lhe dinamismo e transparência. Entre o sistema político, os políticos e a sociedade estabelece-se uma espécie de pacto perverso. As instituições vão se amoldando e falhando porque de algum modo parecem preparadas para transferir imobilismo e ineficiência ao processo da representação e da decisão política, e porque aqueles que deveriam renová-las não o fazem, já que lucram com o mau funcionamento institucional. Põe-se em movimento um círculo diabólico, um circuito de faz-de-conta, de favores, vantagens e compensações, de onde não se sabe bem como sair.

Em segundo lugar, o parlamento é muitas vezes atropelado pela hiperatividade e pelo decisionismo do Executivo. Em vez de sinergia e de colaboração entre os poderes, 
tem-se conflito e competição, quase como se duas lógicas distintas convivessem no mesmo corpo. Os governos em sentido estrito são organismos políticos e administrativos, sustentados não apenas por partidos políticos mas também por burocracias poderosas, que funcionam buscando impor-se sobre o conjunto dos interesses e procurando submeter a si o conjunto dos poderes políticos. A hiperatividade do Executivo é inevitável no mundo em que vivemos. E, ao se colocar em movimento, produz uma complicação adicional para o Legislativo, fazendo com que ele tenha de agir e funcionar de outra maneira. Leva a que a opinião pública, por exemplo, compare a "rapidez" do Poder Executivo com a "lentidão" e a mania de "protelação" do Poder Legislativo, mais ou menos como se do Executivo emanassem apenas decisões e propostas "técnicas" e no Legislativo somente se fizesse política para atrapalhar os governos ou impedir sua ação. Com isso, a imagem pública do parlamento fica ainda mais negativa.

Por fim, também é importante considerar que os parlamentos sofrem um desgaste adicional em sociedades mídia-centradas, nas quais os meios eletrônicos de comunicação tornam-se preponderantes na organização das agendas públicas e das opiniões. Os sistemas democráticos são impelidos a rever suas próprias condições de possibilidade e de funcionamento, já que passam a ter na base pessoas que se posicionam e escolhem segundo orientações e sinais emanados dos meios de comunicação, e não mais dos meios associativos tradicionais ou dos partidos políticos. Aquilo que inquieta (volatilidade do voto, pouca identidade partidária, midiatização e personalização da política, desencanto com as instituições, desideologização e empobrecimento do debate democrático), mostra-se, na verdade, como indício de uma transfiguração sistêmica.

\section{O esvaziamento dos partidos}

Se o governo representativo está em metamorfose, é inevitável que falhe e que, em seu funcionamento cotidiano, não consiga produzir a adesão dos cidadãos. Por sua própria natureza, a metamorfose atinge as próprias capacidades sistêmicas de reação. O sistema fica a contemplar seu próprio enfraquecimento.

Os processos e problemas que estão a minar o Poder Legislativo moderno encontram clara correspondência no plano de um dos protagonistas centrais do sistema representativo: os partidos políticos. A tendência é consistente, não diz respeito somente ao Brasil e atinge às legendas de todo o espectro político-ideológico - da esquerda à direita.

Os partidos não são admirados pelos cidadãos. Não conseguem sequer controlar suas bancadas ou promover a seleção de lideranças que se espera deles. Apresentam listas oportunistas ou pouco densas (pouco representativas) aos eleitores, dando-lhes reduzidas margens de escolha. Os eleitores votam muitas vezes por obrigação, sem 
entusiasmo e sem lealdade: flutuam sobre o processo, mudando de opinião com rapidez, escolhendo de modo mais defensivo e instrumental, movidos a interesse e não a ideias. Ao mesmo tempo, vão reduzindo sua disponibilidade para manter vínculos formais com as legendas partidárias e participar da vida delas.

Como explicar isso? Estarão os partidos decepcionando os eleitores ou são estes que encontraram outra maneira de encaminhar suas reivindicações? O problema é institucional, pode ser resolvido com uma legislação mais justa e adequada? Seria de ordem moral, derivado do "excesso de corrupção" e dos "altos salários" que desgastariam a imagem dos políticos entre a população, como alega uma abrangente corrente de opinião que vai do ultraconservadorismo à extrema-esquerda?

É fácil visualizar o impacto político dessa ausência de vínculos. O enfraquecimento da relação entre partidos e eleitores é um indício de que se afrouxaram os laços entre sociedade e sistema político. Pode ser que os cidadãos já não se importem tanto com o modo como são governados, prefiram distanciar-se da democracia representativa e de todas as suas figuras. Sem os cidadãos, no entanto, a representação soluça e termina sob monopólio dos partidos, que se tornam seus únicos protagonistas, "donos" de suas regras e de seus resultados. Com isso, a política representativa converte-se em atividade de profissionais que não são "vistos" pela sociedade e não se importam em trazê-la para o centro do palco, profissionais que pedem muito e dão pouco em troca.

A questão é delicada porque a democracia representativa continua sempre mais vital em sociedades complexas e multiétnicas como são as nossas. Nesse tipo de sistema democrático, o fundamental papel de imprimir operacionalidade à política, às reivindicações sociais e às decisões de governo tem cabido aos partidos, que foram inventados precisamente para isso.

Os partidos dedicam-se a organizar a chegada ao governo ou à oposição ao governo. Encarregam-se de criar condições para que os interesses parciais desta ou daquela classe evoluam, encontrem-se com os interesses parciais de outras classes e deem origem a algum denominador comum que represente mais fielmente um conjunto de grupos ou mesmo o conjunto da sociedade. Mesmo as organizações de esquerda, que sempre se recusaram a limitar sua ação ao plano estrito do parlamento, representam grupos sociais, dão voz a eles e podem agir como construtores de hegemonia, de novas orientações culturais. São os partidos e a luta entre eles dentro e fora do parlamento que têm possibilitado o processamento democrático das demandas e a estruturação de uma agenda de políticas. Teria terminado essa fase?

Se os cidadãos os ignoram, soa um sinal de alerta, que ecoa mais forte quando se percebe que são escassas as possibilidades de os cidadãos se autorrepresentarem 
ou resolverem seus problemas exclusivamente pela via da "participação direta", sem intermediários.

O esvaziamento dos partidos tem a ver com a mudança profunda que está abalando a ordem social, embaralhando os fluxos de decisão, em uma dinâmica em que o econômico se sobrepõe implacavelmente ao político; a modernidade líquida e a sociedade em rede fazem com que os centros (os governos, os Estados, os partidos) percam potência e não consigam mais controlar espaços e pessoas, que, frustradas e repletas de expectativas, deles se desinteressam. Os cidadãos deixam assim de orientar-se por adesão e lealdade simples, automática, tumultuando as identidades políticas.

Os sistemas políticos (a representação, os parlamentos, os partidos), fortemente sintonizados com o Estado-nação e com os arranjos sociopolíticos nacionais, não poderiam evidentemente passar incólumes por isso; entram em crise porque refletem a constituição de uma nova forma de vida social; tornam-se menos funcionais e menos capazes de interagir de modo virtuoso com sociedades plurais, fragmentadas, reflexivas, velozes e explosivas.

O Brasil conta atualmente com cerca de 30 partidos políticos. Está longe, portanto, de apresentar qualquer tipo de déficit na área. O excesso de partidos não é, por si só, um problema. Pode mesmo ser visto como virtude, expressão de um sistema aberto, democrático, competitivo. O problema é que, em meio ao grande número, somente alguns poucos realmente contam, e mesmo estes não se caracterizam pela firmeza ou pela clareza de propósitos. Praticamente todos estão manchados por algum tipo de imprecisão, vazio doutrinário ou incoerência. A maioria está composta por associações inexpressivas ou meramente fisiológicas, que representam pouco, não fornecem parâmetros valorativos para a cidadania, nem conseguem dizer o que pretendem e como farão para dar vida às suas pretensões. São organizações frágeis, sem magnetismo para manter agregado um punhado de seguidores e de parlamentares que se associaram quase que exclusivamente para incrementarem seus recursos políticos pessoais, não por terem conviç̧ões parecidas e quererem coisas parecidas. Como não foram feitos para isso, não há fidelidade partidária que possa corrigi-los.

Exceção feita às legendas de esquerda e parcialmente ao PT, os partidos brasileiros caracterizam-se pela ausência de caráter programático, já que se constituíram para acomodar pretensões eleitorais tópicas e estratégias políticas imprecisas. Nascidos na maioria dos casos para acomodar interesses e abrir canais de negociação e cooperação com o governo federal, os partidos são mal politizados e se concentram, sem dissimulação, na conquista de recursos políticos, antes de tudo cargos na administração pública. Com isso, a mixórdia de siglas acaba por confundir os eleitores e empurrá-los para a indiferença. 
A relação entre qualidade da representação, número de partidos e mecanismos de criação de novas siglas merece ser sempre bem analisada. As distintas situações nacionais concretas ensejam múltiplos sistemas partidários, seja no que diz respeito às suas regras, seja quanto à maior ou menor facilidade para que se criem novas siglas. Não há de antemão um número ótimo de partidos ou critérios pétreos que fundamentem uma regra para sua multiplicação. A questão de saber quantos partidos suporta uma boa representação democrática é retórica: não há como ser respondida. Democracias de boa qualidade sobrevivem mesmo que tenham sistemas partidários fragmentados; basta que algumas grandes forças partidárias organizem a competição política.

Partidos surgem conforme cálculos e desejos que não estão em manuais. A busca de regulação do processo reflete o desejo das cúpulas de impedir que a representação se despedace e atrapalhe a governabilidade. Especialmente hoje - época de muitas postulações de identidade e múltiplas agendas -, o pluralismo não cabe em uma divisão simples entre direita, centro e esquerda, por exemplo. A imposição de camisas de força não funciona e pode até mesmo afastar do jogo político as minorias não partidarizadas e sem possibilidades para criar seus próprios partidos.

Isso também ocorre nos países em que as tradições históricas, a cultura política e o processo de organização do Estado estabeleceram regimes fortemente polarizados entre duas forças gigantes, como nos Estados Unidos (democratas versus republicanos) e na Inglaterra (conservadores versus trabalhistas). Ali, ou as minorias se compõem e se diluem nos grandes partidos, ou vegetam à margem do sistema, dele se excluindo. Seja como for, sistemas partidários desse tipo são produtos da realidade, não o resultado de imposições legais.

Exceção feita aos períodos ditatoriais, o Brasil sempre foi "multipartidário", sempre conviveu com a proliferação de legendas e com a dança dos parlamentares entre elas. Criar novos partidos tem sido uma marca nacional, funcionando como estratégia para acomodar novos interesses, resolver pendências ou dar vazão a apetites eleitorais.

O problema se agravou a partir dos anos 1980, quando a sociedade ficou mais complexa e se desfez a unidade democrática contra a ditadura. Dezenas de siglas se esparramaram então pela vida política nacional, a maioria com existência fugaz e perfunctória. O mecanismo de criação de partidos ficou desregulado. Tornou-se mais fácil fundar uma legenda. Migrações sem critério entre os partidos tornaram-se usuais.

Fatores tópicos ajudaram a um tal desfecho. Os partidos principais - PMDB, PT, PSDB -, estruturadores do sistema, foram perdendo magnetismo e condicionando 
sua capacidade de atração ao uso dos recursos de poder, ampliados na medida em que conquistavam governos. Desfizeram-se as identidades tradicionais e o surgimento de novas identidades fez com que aumentasse o empenho por novos partidos. A dinâmica democrática geral foi-se mostrando mais forte do que os partidos e esses, ao chegarem aos governos, mal conseguem distinguir-se uns dos outros, fato que passou a ser detectado pela opinião pública, contagiada ela própria por uma visão antipolítica que vitima notadamente os partidos e os parlamentares. Abandonados pelos cidadãos, os partidos foram se concentrando em seus próprios negócios internos, burocratizando-se. Parlamentares mais coerentes passaram a pensar sobre a criação de legendas mais "autênticas" para compensar a indigência partidária prevalecente. Ao mesmo tempo, políticos fisiológicos, sem espaços nos partidos existentes, sentiram-se incentivados a criar legendas à sua imagem e semelhança para assim construírem bases com que viabilizar suas pretensões eleitorais. Por fim, a legislação eleitoral, ao vetar as candidaturas independentes, empurrou os políticos para a multiplicação artificial de legendas. Com a valorização do tempo de propaganda na TV e sua distribuição conforme a votação obtida, o círculo se fechou.

\section{Representação alargada e valorização do parlamento}

A crise que atinge o governo representativo bloqueia a capacidade que o sistema tem de reagir a ela. Mas "por fora" dele - na sociedade mais ampla, na sociedade civil-, a vida continua a produzir política, voz e vontades políticas. A democratização social que acompanha o desenvolvimento da sociedade de massas e a radicalização do moderno faz com que disposições participativas cresçam e pressionem o sistema representativo. A democracia representativa tende a ser ampliada pela infiltração em seu interior de formas diversificadas de "democracia direta".

O efeito virtuoso dessa situação também precisa ser destacado. A sociedade hipermoderna é dinâmica, diversificada, plural e fragmentada demais para acomodar-se nos marcos institucionais de sempre. Ao questioná-los e exigir sua redefinição, faz com que tudo estremeça e perca funcionalidade. Ao mesmo tempo, essa sociedade pressiona em favor de novos espaços de deliberação, de escolha e, por essa via, de representação. Inova o edifício representativo, mantendo a representação no centro, só que de outro modo. Novos institutos e práticas de representação nascem e crescem ao lado das antigas instituições representativas: formas de "orçamento participativo", conselhos gestores, associações civis e organizações não governamentais passam assim a compensar o que houve de perda no campo da representação. Funcionam não como alternativas à representação - expressões de uma democracia participativa que seria oposta à democracia representativa -, mas como mecanismos de complementação que terminam por valorizar a representação. 
Pela via dessas novas instituições e práticas, a representação se alarga e respira, mostrando-se de algum modo reflexiva e reagente às transformações sociais.

Desse ponto de vista, a centralidade adquirida nos sistemas democráticos pela mídia e pelos meios eletrônicos não indica a falência da representação, mas sim o seu ingresso em uma nova etapa, em um novo modelo, sintonizado com a estrutura da vida hipermoderna. Se antes, especialmente nos modelos clássicos, o centro do sistema havia sido ocupado por poucos e seletivos indivíduos de opinião e depois pelos partidos de massa, agora ele passa a ser ocupado pelo "público", ou seja, pelas pessoas que se posicionam e escolhem segundo orientações e sinais emanados dos meios de comunicação. É a terceira "metamorfose da representação" na tipologia de Manin. Nela, aquilo que inquieta (volatilidade do voto, pouca identidade partidária, midiatização e personalização da política, desencanto com as instituições, desideologização e empobrecimento do debate democrático) mostra-se, na verdade, como indício de transfiguração sistêmica.

Como imaginar, então, uma forma de reduzir a distância que há entre a imagem pública negativa do parlamento - tanto a da instituição como a dos parlamentares - e a função positiva que as instituições legislativas têm na democracia contemporânea? Como eliminar ou pelo menos reduzir esse paradoxo? Para falar de maneira positiva, como qualificar a função pública, política, do Poder Legislativo?

São temas que dizem respeito à reorganização do mundo promovida pela globalização do capitalismo, no bojo da qual desponta a questão de saber como reconfigurar os Estados democráticos e instituir uma ordem global pós-nacional. Ainda que seja evidente que o Estado está sendo agredido pela dinâmica da globalização, não estamos ouvindo seu canto fúnebre, nem assistindo a seu colapso. Todos os indícios sugerem que o Estado continuará a ser o principal terreno para a renegociação dos termos da globalização e para a organização da vida em escala global. Se, especialmente a partir dos anos 1980-1990, as principais pressões reformadoras sobre o Estado vieram de setores identificados com o mercado - em luta por uma adaptação dos aparatos estatais à economia capitalista globalizada -, não há porque desconsiderar que outras lógicas reformistas e outros projetos de Estado sempre disputaram palmo a palmo esse terreno, sinalizando para a configuração de arranjos estatais abertos para o social, com políticas públicas universalizantes, mecanismos de regulação do mercado e proteção dos direitos humanos.

A recuperação plena do parlamento e a superação da crise da política integram, assim, o mesmo movimento de reconfiguração do Estado. Trata-se de um movimento de longo prazo e de orientação política e ideológica ainda não claramente estabelecida. Justamente por isso, ele somente pode evoluir de modo virtuoso se não excluir 
ações reformadoras tópicas nos diferentes planos da vida, se, ao contrário, funcionar como um animador geral - um parâmetro de sentido - de reformas políticas e sociais concretas.

A qualificação da função pública do Poder Legislativo precisa, portanto, ser enfrentada em termos mais imediatos e operacionais, nos quais algumas medidas podem ser imaginadas.

a. Uma parte da resposta está no funcionamento sistêmico dos órgãos parlamentares. Aperfeiçoar regimentos internos, melhorar as formas de organização e o desempenho administrativo do parlamento são medidas que têm sido postas em prática com frequência. As casas legislativas não são órgãos mortos, nem simplesmente estão assistindo passivamente a sua decomposição. São órgãos dinâmicos, que estão sempre se recriando e que, em muitos casos (como no Brasil), renovam-se significativamente a cada legislatura. Esse é um caminho que tenderá a produzir bons resultados caso seja privilegiado e valorizado de modo regular. Afinal, é de se esperar que quanto melhor desempenho sistêmico os parlamentos tiverem mais chances terão de se defrontarem com a imagem negativa e superá-la.

b. A melhoria do desempenho sistêmico passa em boa medida pelas pessoas. Não se trata de uma questão de modelo administrativo. Pode ser isso também, mas o fundamental não é isso. Ou se trabalha regularmente para melhorar a qualidade dos quadros, ou as oportunidades diminuem sensivelmente. Programas sistemáticos de formação, de educação técnica e política precisariam ser implementados no interior das casas legislativas, de modo a que se pudesse canalizar, para elas, vida inteligente e atualização constante. O alvo não deveriam ser apenas os quadros de apoio técnico e legislativo - que se tornaram decisivamente indispensáveis -, mas também os quadros imediatamente políticos. Uma boa e competente "classe política" é tão imprescindível quanto a existência de um consistente e bem preparado conjunto de profissionais dedicados a fornecer o devido suporte técnico e administrativo ao trabalho parlamentar.

c. A valorização do parlamento depende ainda, de modo forte e continuado, de reformas no sistema político mais abrangente. Quanto mais democrática e criteriosa forem tais reformas - quanto mais estiverem abertas para a sociedade civil e os interesses da maioria -, mais o Legislativo se recolocará de modo ativo na vida contemporânea. Em boa me- 
dida, o desafio concentra-se em pensar em reformas políticas que não apenas aperfeiçoem a composição dos organismos parlamentares, mas melhorem a relação deles com a sociedade e façam com que a democracia participativa entre em sintonia com a democracia representativa, ajude a revitalizá-la e a fazer com que volte a cumprir uma função decisiva no mundo de hoje. Afinal, a democracia participativa é muito mais sensível aos movimentos da desterritorialização do que a democracia representativa e, ao se integrar com ela e animá-la, pode contribuir para revitalizar o regime democrático como um todo e para repor, em novas bases, a questão da governabilidade.

A perspectiva da "reforma política" pode, então, ser devidamente traduzida: trata-se de um conjunto de medidas e iniciativas voltadas para a promoção de melhorias na governança, na representação e na qualidade da democracia. Em uma palavra, da reforma do governo representativo democrático e da cultura política que o alimenta.

A recuperação da imagem negativa do parlamento, a valorização da sua função positiva e o alcance de uma melhor sintonia entre ele e as condições da vida moderna dependem de movimentos reformadores regulares tanto no nível sistêmico puro (as leis, os regimentos, os sistemas eleitoral e partidário) como na esfera daquilo que o movimenta - as pessoas. Se conseguirmos compor essas duas frentes - a da reforma política e a da reforma das mentalidades -, o avanço será inquestionável. Nesse caso, não apenas os parlamentos funcionarão melhor e terão uma imagem menos negativa, como também o conjunto da vida estatal tenderá a ser positivamente reciclado.

Um "bom" parlamento depende de boas informações e de bons conhecimentos. Necessita de operações técnicas e intelectuais que promovam a autocompreensão das sociedades e o esclarecimento dos cidadãos. Necessita também do poder educativo próprio do trabalho científico: da capacidade que tem a ciência de ensinar, formar e difundir razão crítica. Clareza reformadora e avanços em termos de programas educacionais voltados para o parlamento podem ser obtidos com maior incorporação de pensamento científico.

As hipóteses aqui discutidas não precisam evidentemente ser levadas ao pé da letra, pois as mudanças sociais são assimétricas, espalham-se por tempos longos e demoram a ser captadas pelas instituições. As mudanças nos alertam para o que ocorre nos rios profundos que movem as sociedades. Servem para nos dizer que as instituições precisam mudar, que as práticas não podem permanecer burocratizadas, que a linguagem da política precisa ser renovada, independentemente de credos, livros ou heróis. 


\section{Considerações finais}

O mundo da política está assistindo à alteração de suas formas, de seus sujeitos, de seus discursos. Isso ocorre tanto por força de uma situação objetiva, estrutural, na qual emergem novas agregações sociais, novas subjetividades e novos desafios, quanto por força da desorganização e da suspensão do efeito mobilizador das utopias fundamentais da modernidade.

A situação objetiva deriva da globalização e da configuração de um novo patamar tecnológico, aplicável ao mundo da economia, ao modo de vida, à produção e à difusão de informações. Com a fixação de um novo padrão produtivo, alteram-se sensivelmente as estruturas sociais, as formas do emprego e do trabalho, a composição e as formas de atuação dos grupos sociais. A combinação de informática, internet, grandes redes de comunicação, mídia, televisão e indústria do entretenimento ajuda decisivamente a desgastar e a confundir as instituições políticas, bem como a deslocar a política, convertendo-a em um espetáculo dentre outros, banalizando-a, tirando-Ihe eixo e substância. Diante do desafio, a política reflui e acaba capturada por suas próprias contradições, perdendo eficácia.

O século XXI anuncia-se como estruturado por contextos complexos e turbulentos. Tecnologias sofisticadas, especialistas, imagens frenéticas, arranjos organizacionais que se sucedem sem intervalo, subjetividades que se criam ou se recompõem a cada momento, tudo pressiona a política a se converter em algo mais contido e distante dos cidadãos comuns. O ritmo lento e a natureza sanguínea da política são entendidos como ineficácia, desperdício, insensatez. O horror à política expressa a dificuldade que temos não só de nos adaptarmos a um quadro de crise e de mudança acelerada, mas sobretudo de governá-lo e superá-lo. A política, porém, não é predominantemente isso. É também aposta nas vantagens da coletividade democrática, tanto quanto aposta em uma determinada forma de ampliar as margens de liberdade, interferir nas decisões e reconstruir os fundamentos da vida comum.

No campo ideológico, por sua vez, ao mesmo tempo em que as duas grandes tradições político-culturais da modernidade - a do liberalismo democrático e a do socialismo - se recolhem, intimidadas, projetam-se novos credos, centrados no indivíduo aquisitivo, na hipervalorização do mercado e do econômico, no cidadão como empreendedor, na participação e no "faça-você-mesmo".

Tudo ficou mais obscuro e incerto. O progresso e a barbárie coexistem e se misturam, assustam e confundem. A mundialização estimula a irrupção de fanatismos nacionalistas, a nova economia convive com a exploração de crianças, os avanços da engenharia genética se fazem lado a lado com o crescimento da corrupção. Há 
pouca política no debate político, mas novas modalidades de se fazer política ocupam as dobras do mundo social. Tudo está hoje em discussão e todos têm algo a acrescentar ou a postular o tempo todo. Talvez por estarem exacerbadas, as razões de cada um não são imediatamente transparentes.

A política não parece destinada a soçobrar como espaço de auto-organização da vida coletiva, onde se tomam decisões e se desenham programas de intervenção; onde o conflito se processa tendo em vista o poder e o governo das comunidades. Persiste como o principal instrumento para que se componham diferenças e contradições e para que desejos, vontades e interesses se integrem e sejam coletivamente processados. A política continua a nos oferecer mais chances de domesticar a arrogância e o poder, de fazer com que o conflito produza energia positiva e construa, em vez de paralisar ou destruir. Sua maior promessa é a de fornecer uma oportunidade para que se fundamente uma sociabilidade de novo tipo, solidária e democrática, na qual todos possam coexistir como sujeitos.

Na modernidade tardia e radicalizada, os indivíduos agem e se reúnem para tentar encontrar novas certezas e tomar decisões que os ajudem a escrever suas próprias biografias. Esgotam-se os modelos, crescem dúvidas e dilemas, as agendas permanecem abertas, sofisticam-se as interações discursivas. Discute-se o tempo todo, em um quadro de postulações exacerbadas e de desejo de participação. Identidades e consensos são assim problematizados, a ambivalência chega ao centro do palco. As velhas formas, instituições e certezas da política são desafiadas e postas à prova, mas tudo, ao mesmo tempo, se repõe e se recria. A política já não pode mais ser a mesma, mas não tem como ser sumariamente desalojada do âmago da vida social.

O aumento da tensão entre o movimentar-se e a vida institucional - entre o participar, o "faça-você-mesmo" e o Estado - abala e altera os sistemas políticos, que perdem poder de executar decisões e de produzir consensos e consentimentos, mas também afeta o modo como os movimentos sociais posicionam-se diante dos governos e do sistema político. Já não é mais possível a simples contestação. É preciso interagir com os governos, invadi-los por dentro, contribuir para que se gerenciem problemas cada vez mais complexos. Com isso, o Estado se abre para o social, mas os atores são obrigados a rever suas trajetórias, seus discursos e suas opções. A cibermilitância projeta-se e se combina com novas formas de ação e de organização política.

Em uma sociedade de desigualdades e direitos, de consensos difíceis, em que todos têm voz e em que falham os diferentes centros de comando e de legitimação, a política se vê acossada pela turbulência errática das ações coletivas e individuais. As instituições ficam cercadas e sobrecarregadas de demandas. Fraquejam, ainda 
que não deixem de operar. A política, porém, encontra novos caminhos. Fóruns ampliados de negociação, novas modalidades de gestão e de deliberação, ativismos de novo tipo e protagonismos surpreendentes parecem sugerir uma superação do monopólio dos especialistas e uma abertura da estrutura de tomada de decisões.

A reorganização hipercapitalista do mundo carrega no ventre um cenário dramático, simbolizado pela corrosão dos talentos políticos, pela desmontagem dos arranjos coletivos com que se protegiam as sociedades, pelo esvaziamento das instituições e pela subversão dos circuitos espaço-temporais que forneciam parâmetros para a vida. Devemos, porém, pensar o tema com os olhos para frente. Se é verdade que o capitalismo turbinado das últimas décadas tem sido devorador da sociedade - estilhaçando a vida coletiva e roubando protagonismo dos grupos em benefício dos mercados -, também é verdade que ele manteve ativa a dimensão estrutural e subjetiva do conflito, da contradição, da luta pela existência. A sociedade não morreu; foi apenas redefinida. A política não desapareceu; foi desorganizada e posta em um plano mais técnico que ético, que não emociona nem inspira confiança. Ela precisa ser plenamente reabilitada: repolitizada, de modo a que o conflito substantivo, as ideologias e os cidadãos sejam postos de novo no coração do Estado.

Como aposta nas vantagens da comunidade, a política é acima de tudo aposta na participação política (Nogueira, 2005): disposição cidadã para interferir no rumo das coisas e ativar aqueles processos que dizem respeito a todos e a todos comprometem. É aposta na ação democrática que se dedica a refundar o poder, a transformá-lo em algo mais acessível, menos ameaçador, mais compartilhado. A política democrática, deste ponto de vista, qualifica-se pela preocupação em fazer com que o participar afirme-se como parceiro do governar e do representar, tanto quanto em tentar garantir que o diálogo prevaleça como forma de expressar e resolver conflitos entre as partes da sociedade. Preocupação essa que é também a maior promessa da representação política democrática.

Abstract: Assuming from the very beginning that contemporary democracies cannot work without active parliaments, this article deals with the recurrent image of the "crisis of representation" of the modern State, that is, with the latter's alleged difficulties to fulfill some of the strategic roles demanded by complex societies in recent times. I contend that the problems of legitimacy in today's political systems are linked with the crisis of the State triggered by the new economic and social structures of contemporary capitalism. According to my hypothesis, the transformations of capitalist society - i.e., of hypermodernity - jeopardized and bypassed representation, which is now facing serious operational issues.

Key-words: representation, democracy, State, politics, parliament. 


\section{Referências}

BAUMAN, Z. Modernidade líquida. Rio de Janeiro: Jorge Zahar, 2001.

Boвbı, N. O futuro da democracia. 7. ed. rev. e amp. São Paulo: Paz e Terra, 2000.

CAStells, M. A sociedade em rede. São Paulo: Paz e Terra, 1999.

MANIN, B. Principes du gouvernment représentatif. Paris: Flammarion, 1996.

Nogueira, M. A. Um Estado para a sociedade civil. Temas éticos e políticos da gestão democrática. 3. ed. São Paulo: Cortez, 2011.

—. Em defesa da política. 2. ed. São Paulo: Editora Senac, 2005.

PITKIN, H. F. Representação: palavras, instituições e ideias. Lua Nova, n. 67. São Paulo, 2006, p. 15-47.

URBINATI, N. O que torna a representação democrática? Lua Nova, n. 67. São Paulo, 2006, p. 191-228. 